\title{
Increase in erythrocyte osmotic resistance following polyunsaturated fatty acids (PUFA) supplementation in show jumper horses
}

\author{
M. Bazzano, M. Rizzo, F. Arfuso, C. Giannetto, F. Fazio, G. Piccione* \\ Department of Veterinary Sciences, University of Messina, Messina, Italy
}

\section{A R T I C L E I N F O}

Article history:

Received 18 February 2015

Received in revised form

22 August 2015

Accepted 24 August 2015

\section{Keywords:}

Erythrocyte osmotic fragility

Polyunsaturated fatty acids

Physical exercise

Horse

\begin{abstract}
A B S T R A C T
Osmotic fragility test has been used to study the influence of different factors on the osmotic properties of cell membranes. Considering the importance of polyunsaturated fatty acids (PUFA) in biological functions we aimed to investigate the effects of dietary PUFA supplementation on erythrocyte osmotic fragility (EOF), blood lactate (BL), hematocrit (Hct), red blood cell (RBC), hemoglobin (Hb), and mean cell volume (MCV) in 10 jumper horses. Two events occurred prior to start supplementing horse's diet and two events occurred after 4 weeks PUFA supplementation. Five horses received the PUFA supplementation (Group A), and five served as controls (Group B). Blood samples were taken before and after each course. The statistical analysis revealed significant increase in BL, Hct, RBC and Hb following exercise $(P<0.0001)$. However, the interaction between exercise and PUFA supplementation $(P=0.0083)$ showed PUFA-supplemented horses having a smaller rise in BL levels $(P=0.0107)$ following exercise. Significant interactions between exercise and PUFA treatment were also found on EOF levels $(P<0.05)$. The hemolysis curves showed PUFA-supplemented horses exhibiting a reduction in EOF compared to controls $(P<0.05)$. Although hemolysis never occurred at $0.9 \% \mathrm{NaCl}$ concentration, jumping exercise determined an increase in EOF $(P=0.0014)$ at $0.8 \% \mathrm{NaCl}$ solution. A significant interaction between exercise and PUFA treatment $(P=0.0022)$ was found showing PUFA-supplemented horses having lower EOF $(P=0.0015)$ following exercise. The assessment of EOF is a suitable indicator of athletic performance. The results showed that PUFA supplementation might exert beneficial effects on the horse body system by enhancing the performance in high-level show jumpers.
\end{abstract}

(c) 2015 Published by Elsevier B.V.

\section{Introduction}

The degree of resistance of red blood cells (RBC) to lysis, as a result of a decrease in the sodium chloride $(\mathrm{NaCl})$ concentration of their environment, is the basis of the erythrocyte osmotic fragility (EOF) test. Experimentally, the conventional osmotic fragility test consists of measuring the intensity of light transmitted through a hemoglobin $(\mathrm{Hb})$ solution produced by suspension of erythrocytes in a hypotonic media. The light wavelength commonly used is $\lambda=540 \mathrm{~nm}$, where only hemoglobin, as a major protein of the RBC, contributes to light absorption. Osmotic fragility is defined by shifts in the hemolysis curve, which relates absorbance versus $\mathrm{NaCl}$ concentration (Walski et al., 2014). Osmotic fragility is widely used to elucidate mechanisms of the influence of different factors on the osmotic properties of RBC membranes, such as shear stress and mechanical hemolysis, drugs (Sowemimo-Coker, 2002),

\footnotetext{
* Correspondance author: Department of Veterinary Sciences. Polo Universitario Annunziata, University of Messina. 98168, Messina, Italy. Fax: + 390903503975.

E-mail address: giuseppe.piccione@unime.it (G. Piccione).
}

temperature (Pribush et al., 2003), ultrasound effects and irradiation (Ivanov, 1999). A number of researches investigated the effects of diet and dietary polyunsaturated fatty acids (PUFA) on EOF in humans (Hagve et al., 1993), rats (Ehrstrom et al., 1981; Hagve et al., 1991), heifers (Colin-Negrete et al., 1996), rabbits (van den Berg et al., 1991; Kogawa et al., 1998), sheep (Shand and Noble, 1981), and pigs (Cools et al., 2011). Special attention was paid to the dietary content of PUFA, particularly eicosapentaenoic acid (EPA) and docosahexanoic acid (DHA), as it reflects the fatty acids composition of several tissue cells including erythrocytes (Fischer and Black, 1991; Stark, 2008). EPA and DHA are incorporated into the cell membrane modifying its composition as well as the membrane-related characteristics (Cools et al., 2011). However, the influence of PUFA supplementation on EOF has not been investigated in equine species. Apart from diet, physical exercise can affect several erythrocyte characteristics as well.

Efficient delivery and release of oxygen to exercising muscles by RBC are important determinants of athletic performance. Many authors have suggested that physical exercise accelerates the rate of $\mathrm{RBC}$ turnover and can, in some cases, lead to the so-called 
condition of sports anemia which may results in decreased capacity for physical activity (Smith et al., 1995). In addition, exercise could lead to change in lipid composition of the cell membrane due to blood $\mathrm{pH}$ changes and/or oxidative damage which affect the cellular osmotic homeostasis and facilitate cellular dehydration. In this way, osmotic stress to RBC during exercise may increase their susceptibility to irreversible damage and destruction (Smith et al., 1995; Hanzawa and Watanabe, 2000), compromising the performance. Therefore, the evaluation of the degree of resistance of RBC during exercise by a fast and easy analysis as EOF test, has acquired great interest in sport physiology.

Exercise intensity and duration influences erythrocyte properties in human (Smith et al., 1995; Berzosa et al., 2011) and equine (Hanzawa and Watanabe, 2000; De Moffarts et al., 2007) athletes. Different results were obtained analyzing the influence of exercise on horse EOF. Hanzawa et al. (1999a) found higher EOF in Thoroughbreds after maximal exercise. Decreasing EOF was found in Thoroughbreds and Quarter horses after short distance treadmill exercise (Smith et al., 1989). However little information is available to equine researchers about the effect of specific exercise such as show jumping course on erythrocyte properties. Based on the present knowledge about equine physiology, we aimed to study changes in some erythrocyte parameters, focusing on EOF, in show jumper horses during 2-day high level national jumper classes before and after 4-week dietary supplementation with PUFA.

\section{Materials and method}

\subsection{Animals}

Ten clinically healthy and regularly trained show jumping horses ( 6 mares and 4 geldings, mean age $8.1 \pm 1.5$ years; mean body weight $470 \pm 30 \mathrm{~kg}$ ) were investigated in Sicily during Spring 2014. Animals were stabled in individual boxes $(3.5 \times 3.5 \mathrm{~m})$ at the same training center under natural photoperiod (sunrise at 05:00 $\mathrm{AM}$, sunset at $07.00 \mathrm{PM}$ ) and $18-22^{\circ} \mathrm{C}$ mean environmental temperature. Horses were fed three times daily (06.00 AM; 12.00 AM; $06.00 \mathrm{PM}$ ), the food intake was about $2.5 \%$ of horse body weight and water was available ad libitum. The diet consisted of $8 \pm 1 \mathrm{~kg} /$ day dried grass hay (crude protein $9 \%$, crude fiber $35 \%$, Ca $0.4 \%, P$ $0.23 \%$ ) and $4 \pm 0.5 \mathrm{~kg} /$ day commercially available concentrates (crude protein $14 \%$, crude fat $4.8 \%$, crude fibre $9 \%$, ash $9.6 \%$, Ca $1.2 \%$, P 0.6\%; vitamins and trace-elements $/ \mathrm{kg}$ concentrate: Vit A 26,000IU; Vit $D_{3}$ 3,200; Vit E 170 mg; Vit K 2.5 mg; Vit $B_{1} 12 \mathrm{mg}$; Vit $B_{2} 18$ mg; Vit $B_{12} 0.03$ mg; PP 180 mg; Fe 115 mg; Cu 42 mg; Zn $170 \mathrm{mg}$; Se $0.6 \mathrm{mg}$ ). During the experimental period, horses exercised for $45 \pm 10 \mathrm{~min} / \mathrm{day}$, six days per week, continuing the specific show jumper-training program (Hodgson and Rose, 1994) they were accustomed.

\subsection{Study design}

The animals were divided into two equal groups: the experimental group A (PUFA-supplemented) received the Omega Horse ${ }^{\circledR}$ PUFA supplement (NBF Lanes, Milan, Italy), the control group B received no supplementation during the experimental period.

PUFA-supplemented horses received total n-3 PUFA 22.5 g, EPA $11.5 \mathrm{~g}$ and DHA $7.7 \mathrm{~g}$, daily for 30 -days period (Table 1 ). The supplement was palatable and easily miscible with concentrates, and a groom systematically verified the consumption of supplement. The treatment was well tolerated by the horses and no adverse reaction was observed.

All horses competed in 2-day high-level national jumper class, categories C135/C140 according to the Federazione Italiana Sport Equestri (FISE) rules, prior to start dietary supplementation (C1
Table 1

Polyunsaturated fatty acids supplement Omega Horse $^{\mathbb{R}}$ composition.

\begin{tabular}{lc}
\hline Active principle & Content \% \\
\hline$\alpha$-Myristic acid (C12:0) & 7.0 \\
Palmitic acid (C13:0) & 18.0 \\
Palmitoleic acid (C16:1) & 9.5 \\
Stearidonic acid (C18:0) & 4.5 \\
Oleic acid (C18:1) & 19.0 \\
Linoleic acid (C18:2) & 1.5 \\
$\alpha$-linolenic acid (C18:3) & 0.5 \\
Eicosapentaenoic acid, EPA (C20:5) & 18.0 \\
Docosapentaenoic acid (C22:5) & 4.0 \\
Docosahexaenoic acid, DHA (C22:6) & 12.0 \\
Other unsaturated fatty acids & 5.8 \\
Vitamin E & 0.2 \\
Butylhydroxytoluene, BHT & 0.015 \\
\hline
\end{tabular}

and C2). Further 2-day high-level national jumper class (C3 and C4) occurred after 4-week PUFA supplementation. Each jumping course was preceded by a warm-up consisting of walk ( $8 \pm 2 \mathrm{~min}$ ), trot $(8 \pm 1 \mathrm{~min})$, canter $(5 \pm 1 \mathrm{~min})$ and 6 trial obstacles ( 3 verticals and 3 oxers, height $110 \pm 30 \mathrm{~cm}$ ). Technical characteristics of each jumping course are indicated in Table 2. All horses competed in the afternoon (12.00 AM-02.00 PM) and were subjected to blood sampling before exercising, at rest in the stall ( $\left.\mathrm{C}_{\mathrm{PRE}}\right)$, and within 10 minutes after the competition $\left(\mathrm{C}_{\mathrm{POST}}\right)$.

The riders, trainer and technician performing laboratory analyses were blind to treatment during the study.

All treatments, housing and animal care reported above were carried out in accordance with the standards recommended by the EU Directive 2010/63/EU for animal experiments.

\subsection{Blood analysis}

Blood samples were collected by jugular venipuncture into EDTA-vacutainer test tubes in order to assess blood lactate (BL), hematocrit (Hct), red blood cell (RBC), hemoglobin ( $\mathrm{Hb})$, mean cell volume (MCV), and EOF. A portable blood lactate analyzer (Accusport, Boehringer, Germany) was used to determine BL concentration immediately following sample collection. Further analyses of the samples were performed at the laboratory within three hours from the collection. Hct, RBC, Hb and MCV were assessed using an automatic analyzer (HeCo Vet C, SEAC, Florence, Italy). The determination of EOF was performed using a $\mathrm{NaCl}$ solution prepared as described by Faulkner and King (1970). Particularly, 10 different concentrations of $\mathrm{NaCl}$ solution ranging from $0.0 \%$ to $0.9 \%$ were prepared. A set of 10 test tubes containing $10 \mathrm{ml}$ of different $\mathrm{NaCl}$ solution $(0.0-0.9 \%)$ was charged with $0.02 \mathrm{ml}$ of blood. After gently mixing, the test tubes were maintained at room temperature $\left(26-27^{\circ} \mathrm{C}\right)$ for $30 \mathrm{~min}$. Thereafter the content of the

Table 2

Technical characteristics of the show jumping courses (C1, C2, C3, C4): obstacle height (Height), course length (Length), maximal time allowed to perform the course (Time), number of obstacles (Efforts), obstacle types (Verticals, Oxers, Double/Triple Combinations).

\begin{tabular}{lllll}
\hline & C1 & C2 & C3 & C4 \\
Technical characteristics & & & & \\
\hline Height $(\mathbf{c m})$ & 135 & 135 & 135 & 140 \\
Length (m) & 670 & 500 & 650 & 480 \\
Time $(\mathbf{s})$ & 110 & 86 & 106 & 83 \\
Efforts Verticals & 6 & 9 & 8 & 8 \\
$\quad$ Oxers & 8 & 6 & 6 & 6 \\
$\quad$ Combinations & 2Doubles & 1Double & 2Doubles & 1Double \\
& & 1Triple & & 1Triple \\
\hline
\end{tabular}


test tubes was re-mixed and centrifuged at $327 \mathrm{~g}$ for $15 \mathrm{~min}$. The supernatant of each test tube was transferred into a glass cuvette to assess the $\mathrm{Hb}$ concentration by measuring the absorbance at $540 \mathrm{~nm}$ by UV Spectrophotometer (Slim SEAC, Florence, Italy). The degree of hemolysis was expressed as percentage, considering $100 \%$ as the maximum hemolysis value of $0.0 \% \mathrm{NaCl}$ solution. The percentage of hemolysis was calculated using the following formula (Faulkner and King, 1970):

Hemolysis (\%): (OD of test/OD of distilled water) $\times 100$

\subsection{Where OD is Optical Density}

The EOF curve was obtained by plotting the hemolysis percentage against the $\mathrm{NaCl}$ concentration. The same procedure was applied to each blood sample collected from the horses enrolled in the study.

\subsection{Statistical analysis}

Two-way repeated measures analysis of variance (ANOVA) was applied to determine statistical effect of physical exercise and PUFA treatment on BL, Hct, RBC, Hb, MCV, and EOF in jumper horses during four experimental jumping courses. When statistical significances $(P<0.05)$ were found the Bonferroni post hoc comparison test was applied. Statistical analysis was performed using the PRISM 6 statistical software (GraphPad Software Inc., La Jolla, California).

\section{Results}

All the horses included in the study completed each jumping course within the time allowed and without refusals.

The mean values \pm standard deviations of BL, Hct, RBC, Hb and MCV together with the related statistical significances are shown in Table 3. Concentrations of BL were increased by exercise $(P<0.0001)$, although an interaction between exercise and PUFA treatment $(P=0.0083)$ showed PUFA-supplemented horses (Group A) having a smaller rise in BL levels $(P=0.0107)$ than control horses (Group B) following exercise at $\mathrm{C}_{\text {POST }}$ and $C 4_{\text {POST }}$.

A significant increase in Hct, RBC and Hb values $(P<0.0001)$ was recorded in both groups after each jumping course.

Two-way ANOVA revealed statistical differences in EOF between Group A and Group B at different $\mathrm{NaCl}$ solutions and among show jumping courses. In particular, Group A exhibited statistically lower hemolysis percentages compared to Group B at each $\mathrm{NaCl}$ concentration. As showed in Fig. 1 the more representative differences occurred at $\mathrm{NaCl} 0.8 \% \quad(P=0.0015), \quad \mathrm{NaCl} 0.6 \%$ $(P=0.0001), \mathrm{NaCl} 0.4 \%(P=0.0001)$ and $\mathrm{NaCl} 0.1 \%(P=0.0379)$.

Although a reduction in EOF was observed in Group A after the C4 course, no significant difference was found compared to Group B.

Significant interactions between exercise and PUFA treatment were observed on EOF $(P<0.05)$ at different $\mathrm{NaCl}$ solutions but $0.3 \% \mathrm{NaCl}$. According to the hemolysis curves (Fig. 2), PUFA-supplemented horses exhibited a reduction in EOF values $(P<0.05)$ compared to controls at $\mathrm{C}_{\mathrm{PRE}}$ and C3 $3_{\text {POST }}$.

Hemolysis never occurred at $0.9 \% \mathrm{NaCl}$ concentration, however, physical exercise led to an increase in $\operatorname{EOF}(P=0.0014)$ at $0.8 \% \mathrm{NaCl}$ solution by determining an increase in the percentage of hemolysis at $\mathrm{C} 1_{\text {POST }}$ and $\mathrm{C} 2_{\mathrm{POST}}$ compared to $\mathrm{C} 1_{\mathrm{PRE}}$ and $\mathrm{C} 2_{\mathrm{PRE}}$. However, the interaction between exercise and PUFA treatment $(P=0.0022)$ showed PUFA-supplemented horses having lower EOF $(P=0.0015)$ following exercise.
Table 3

Mean values + standard deviations of blood lactate $(\mathrm{BL})$, hematocrit $(\mathrm{Hct})$, red blood cell (RBC), hemoglobin ( $\mathrm{Hb}$ ) and mean cell volume (MCV) recorded in Group A (PUFA-supplemented horses) and Group B (control horses), before (PRE) and after (POST) the show jumping courses (C1, C2, C3, C4).

\begin{tabular}{|c|c|c|c|c|c|}
\hline $\begin{array}{l}\text { Blood para- } \\
\text { meters }\end{array}$ & Groups & C1 & C2 & C3 & C4 \\
\hline BL (mmol/l) & $\begin{array}{l}A_{P R E} \\
A_{P O S T} \\
B_{P R E} \\
B_{P O S T}\end{array}$ & $\begin{array}{l}1.4 \pm 0.4 \\
3.3 \pm 0.7^{\mathrm{a}, \mathrm{b}} \\
1.5 \pm 0.3 \\
3.2 \pm 0.3^{\mathrm{a}, \mathrm{b}}\end{array}$ & $\begin{array}{l}1.4 \pm 0.4 \\
3.3 \pm 0.4^{\mathrm{a}, \mathrm{b}} \\
1.7 \pm 0.2 \\
3.6 \pm 0.3^{\mathrm{a}}\end{array}$ & $\begin{array}{l}1.6 \pm 0.4 \\
3.4 \pm 0.4^{\mathrm{a}, \mathrm{b}} \\
1.7 \pm 0.3 \\
4.2 \pm 0.6^{\mathrm{a}}\end{array}$ & $\begin{array}{l}1.8 \pm 0.4 \\
2.8 \pm 0.3^{\mathrm{a}, \mathrm{b}} \\
1.7 \pm 0.2 \\
3.7 \pm 0.3^{\mathrm{a}, \mathrm{d}}\end{array}$ \\
\hline Hct (\%) & $\begin{array}{l}A_{P R E} \\
A_{P O S T} \\
B_{P R E} \\
B_{P O S T}\end{array}$ & $\begin{array}{l}35.4 \pm 4.5 \\
45.9 \pm 4.1^{\mathrm{a}} \\
35.0 \pm 4.6 \\
45.4 \pm 4.3^{\mathrm{a}}\end{array}$ & $\begin{array}{l}34.6 \pm 3.5 \\
47.5 \pm 3.7^{\mathrm{a}} \\
34.4 \pm 3.6 \\
47.0 \pm 3.6^{\mathrm{a}}\end{array}$ & $\begin{array}{l}32.7 \pm 5.8 \\
42.8 \pm 6.1^{\mathrm{a}} \\
32.3 \pm 1.3 \\
44.9 \pm 1.5^{\mathrm{a}}\end{array}$ & $\begin{array}{l}33.0 \pm 5.1 \\
42.9 \pm 6.8^{\mathrm{a}} \\
32.5 \pm 1.6 \\
48.8 \pm 3.3^{\mathrm{a}, \mathrm{d}, \mathrm{c}}\end{array}$ \\
\hline $\operatorname{RBC}\left(10^{6} / \mu \mathrm{l}\right)$ & $\begin{array}{l}A_{P R E} \\
A_{P O S T} \\
B_{P R E} \\
B_{P O S T}\end{array}$ & $\begin{array}{l}7.7 \pm 1.0 \\
9.8 \pm 1^{\mathrm{a}} \\
7.3 \pm 1.1 \\
9.5 \pm 1^{\mathrm{a}}\end{array}$ & $\begin{array}{l}7.4 \pm 0.9 \\
9.9 \pm 0.8^{\mathrm{a}} \\
7.1 \pm 0.9 \\
9.9 \pm 0.7^{\mathrm{a}}\end{array}$ & $\begin{array}{l}7.3 \pm 1.4 \\
9.1 \pm 1.3^{\mathrm{a}} \\
6.6 \pm 0.4 \\
9.4 \pm 0.4^{\mathrm{a}}\end{array}$ & $\begin{array}{l}7.3 \pm 1.3 \\
9.8 \pm 1.9^{\mathrm{a}} \\
6.7 \pm 0.3 \\
9.8 \pm 0.9^{\mathrm{a}}\end{array}$ \\
\hline Hb (g/dl) & $\begin{array}{l}A_{P R E} \\
A_{P O S T} \\
B_{P R E} \\
B_{P O S T}\end{array}$ & $\begin{array}{c}11.8 \pm 1.5 \\
15.2 \pm 1.5^{\mathrm{a}} \\
11.6 \pm 1.5 \\
14.6 \pm 1.5^{\mathrm{a}}\end{array}$ & $\begin{array}{c}11.5 \pm 1.3 \\
15.8 \pm 1.5^{a} \\
11.2 \pm 1.3 \\
15.6 \pm 1.5^{a}\end{array}$ & $\begin{array}{l}11.8 \pm 2.2 \\
14.4 \pm 2.2^{\mathrm{a}} \\
11.3 \pm 0.5 \\
14.6 \pm 0.4^{\mathrm{a}}\end{array}$ & $\begin{array}{c}11.5 \pm 1.3 \\
14.1 \pm 1.9^{\mathrm{a}} \\
11.4 \pm 0.4 \\
15.5 \pm 0.9^{\mathrm{a}}\end{array}$ \\
\hline $\operatorname{MCV}(f L)$ & $\begin{array}{l}A_{P R E} \\
A_{P O S T} \\
B_{P R E} \\
B_{P O S T}\end{array}$ & $\begin{array}{l}45.9 \pm 1.2 \\
46.8 \pm 1.3 \\
48.1 \pm 0.8 \\
47.8 \pm 0.7\end{array}$ & $\begin{array}{l}47.0 \pm 0.8 \\
47.7 \pm 1.4 \\
48.6 \pm 2.0 \\
47.5 \pm 1.4\end{array}$ & $\begin{array}{c}46.7 \pm 13 \\
48 \pm 12 \\
48.7 \pm 3.8 \\
47.9 \pm 3.3\end{array}$ & $\begin{array}{l}45.5 \pm 1.1 \\
44.4 \pm 5.1 \\
48.6 \pm 3.5 \\
50.0 \pm 7.01\end{array}$ \\
\hline
\end{tabular}

Significances:

a vs $C_{\mathrm{PRE}}$ within the group $(P<0.0001)$

${ }^{b}$ vs Group B at C3 $(P=0.0107)$.

c vs Group A at C3 $(P<0.0001)$.

${ }^{\mathrm{d}}$ vs Group A at $C 4(P<0.0001)$

\section{Discussion}

The significant increase in BL concentrations recorded after each course confirmed that the anaerobic metabolism makes a significant, although not exclusive, contribution to the energy supply in a show jumper. Effectively, the relatively slow average speed maintained during the course, belies the intense effort required to jump a sequence of fences (Hodgson and Rose, 1994). However, after 4-week PUFA treatment the increase in BL at C3 3 Post and $\mathrm{C4}_{\text {POST }}$ was significantly lower in PUFA-supplemented horses than controls. This result might reflect a modification in energy metabolism consisting of an increased utilization of fatty acids with a sparing of glucose and thus a reduction in BL following the physical effort. This finding is consistent with previous studies hypothesizing an enhanced uptake of fatty acids by muscle cells in exercising horses following the administration of dietary PUFA (O'Connor et al., 2004; Piccione et al., 2014). The significant increase in Hct, RBC and Hb values recorded in both groups after each jumping course was likely due to the splenic contraction, as it is well known that the equine spleen function as reservoir of 4121 of red blood cells that can be released into circulation at the beginning of exercise (Hinchcliff et al., 2004). Although hemolysis never occurred at $0.9 \% \mathrm{NaCl}$ concentration, physical effort was found to affect EOF at $0.8 \% \mathrm{NaCl}$ solution by determining an increase in the percentage of hemolysis at $\mathrm{C}_{\text {POST }}$ and $\mathrm{C} 2_{\mathrm{POST}}$ compared to $\mathrm{C} 1_{\mathrm{PRE}}$ and $\mathrm{C} 2_{\mathrm{PRE}}$. These results are consistent with previous studies on EOF in exercising horses (Hanzawa and Watanabe, 2000) that found a higher EOF after maximal exercise (Hanzawa et al., 1999a). However, PUFA-supplemented horses showed a reduction in EOF at C3 $3_{\text {POST }}$ and C4 $4_{\text {POST }}$ compared to C3 $3_{\text {PRE }}$ and C4 $4_{\text {PRE. }}$ 

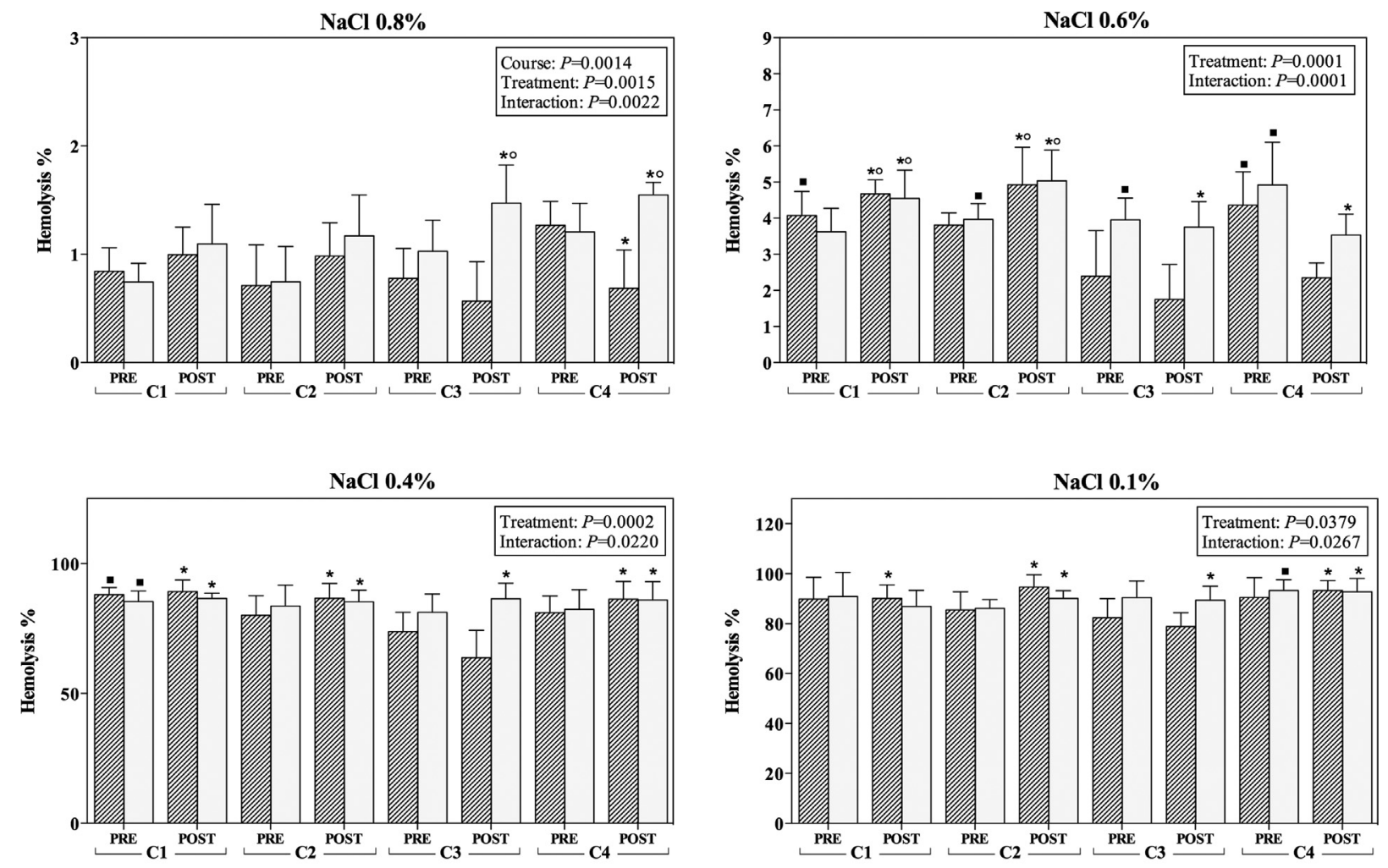

\section{WTA Group A $\square$ Group B}

\section{Significances us Group A: " vs $\mathrm{C}_{\mathrm{PRE}} * \mathrm{vs}_{\mathrm{COST}}{ }^{\circ}$ vs $\mathrm{C} 4 \mathrm{POST}$}

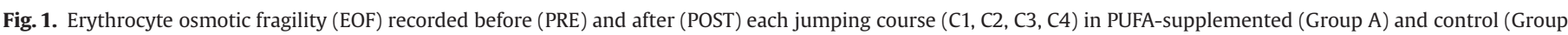

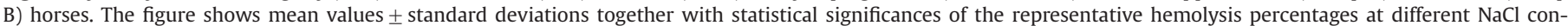
centrations $(0.8 \%, 0.6 \%, 0.4 \%$ and $0.1 \%)$ during the experimental period. $P$ values were shown in the frame of each $\mathrm{NaCl}$ solution.

In the authors' opinion, this finding might be the result of two concurrent modifications occurring in the horse body system following PUFA supplementation. The first cause consists in BL changes that directly influenced blood pH (Hinchcliff et al., 2004). After maximal exercise equine blood $\mathrm{pH}$ decreases from 7.4 to 7.0 (Carlson, 1995) as a consequence of the increase in lactate and carbon dioxide partial pressure in blood, the resulting decrease in blood $\mathrm{pH}$ promotes the osmotic fragility of erythrocytes (Hanzawa and Watanabe, 2000). Therefore, the lower BL concentration recorded in PUFA-supplemented horses at C $3_{\text {POST }}$ and C4 $4_{\text {POST }}$ might have determined a limited decrease in blood $\mathrm{pH}$ and a reduced hemolysis percentage consequently. The second cause is the membrane cell that changes its composition and properties following PUFA supplementation. A previous in vitro study by Bruno et al. (2007) demonstrated that DHA (and other PUFA) might modulate membrane protein function by bilayer-mediated mechanisms involving changes in bilayer material properties. Modification in cell membrane composition alters the membrane-related properties such as the osmotic fragility (Cools et al., 2011). Previous studies on rats (Ehrstrom et al., 1981; Hagve et al., 1991) and humans (Hagve et al., 1993) found a significant decrease in EOF following a dietary supplementation with n-3 fatty acids. In agreement with these studies, we also reported a reduction in EOF in horses supplemented with PUFA. After 4-week PUFA treatment, the hemolysis curve displayed PUFA-supplemented horses exhibiting lower hemolysis percentage before and after the jumping course C3. Although a reduction in EOF was observed in PUFAsupplemented horses after the C4 course, no significant difference was found compared to control group. This finding might be due to the presence of erythrocytes released by the spleen following the physical effort of $\mathrm{C} 3$ course. Effectively, the stagnantly pooled erythrocytes in the spleen could accelerate membrane lipid alteration (Hanzawa et al., 1999b) that could mask the influence of PUFA on EOF.

\section{Conclusion}

To the best authors' knowledge, this is the first study investigating the influence of physical exercise during high-level jumping classes, before and after dietary supplementation with PUFA, on erythrocyte osmotic resistance of show jumper horses. The horses in the present study showed a significant increase in hemolysis percentage after the show jumping courses compared to the rest values. However, horses supplemented with PUFA showed reduced erythrocyte osmotic fragility and decreased blood lactate following exercise compared to the control group.

The results showed that PUFA supplementation might exert beneficial effects on the horse body system by enhancing the performance in high-level show jumpers.

\section{Acknowledgments}

The authors wish to thank the New Eagles equestrian training center (Catania, Italy) and Mr. Ciro Carrabotta for providing horses 

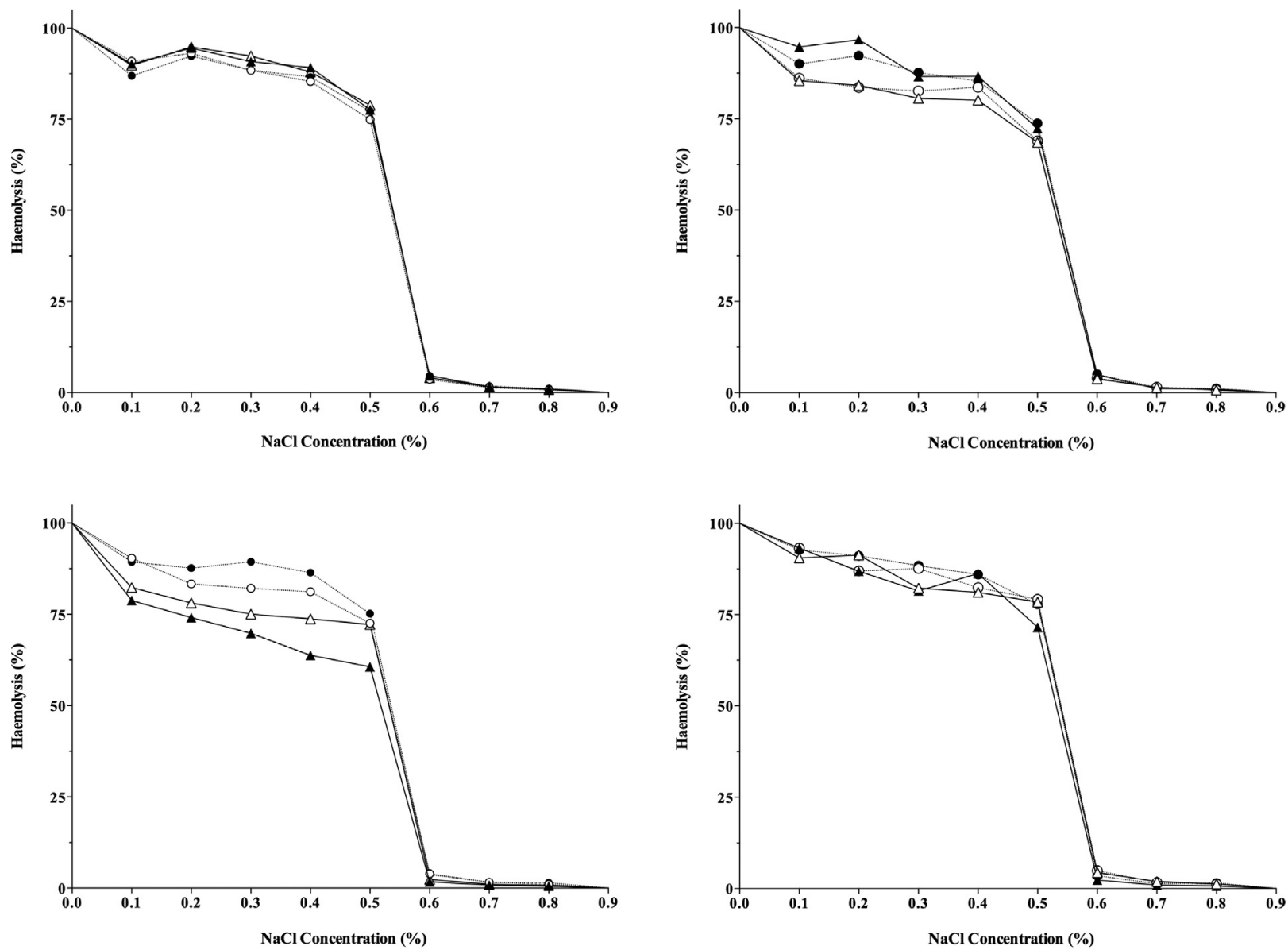

$\triangle$ Group A $A_{\text {PRE }}$

\section{Group $A_{\text {POST }}$}

O- Group B BRE

- Group B Bost

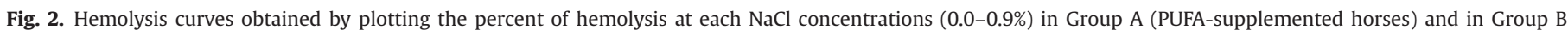
(control horses) before (PRE) and after (POST) each jumping course (C1, C2, C3, C4).

and collaboration during the study.

\section{References}

Berzosa, C., Gomez-Trullen, E.M., Piedrafita, E., Cebrian, I., Martinez-Ballarin, E., Miana-Mena, F.J., Fuentes-Broto, L., Garcia, J.J., 2011. Erythrocyte membrane fluidity and indices of plasmatic oxidative damage after acute physical exercise in humans. Eur. J. Appl. Physiol. 111, 1127-1133.

Bruno, M.J., Koeppe II, R.E., Andersen, O.S., 2007. Docosahexaenoic acid alters bilayer elastic properties. Proc. Natl. Acad. Sci. 104, 9638-9643.

Carlson, G.P., 1995. Interrelationships between fluid, electrolyte and acid-base balance during maximal exercise. Equine Vet. J. 18, 261-265.

Colin-Negrete, J., Kiesling, H.E., Ross, T.T., Smith, J.F., 1996. Effect of whole cottonseed on serum constituents, fragility of erythrocyte cells, and reproduction of growing Holstein heifers. J. Dairy Sci. 79, 2016-2023.

Cools, A., Maes, D., Papadopoulos, G., Vandermeiren, J.A., Meyer, E., Demeyere, K., De Smet, S., Janssens, G.P.J., 2011. Dose-response effect of fish oil substitution in parturition feed on erythrocyte membrane characteristics and sow performance. J. Anim. Physiol. Anim. Nutr. 95, 125-136.

De Moffarts, B., Portier, K., Kirschvink, N., Coudert, J., Fellmann, N., van Erck, E., Letellier, C., Motta, C., Pincemail, J., Art, T., Lekeux, P., 2007. Effects of exercise and oral antioxidant supplementation enriched in (n-3) fatty acids on blood oxidant markers and erythrocyte membrane fluidity in horses. Vet. J. 174, $113-121$.

Ehrstrom, M., Harms-Ringdahl, M., Alling, C., 1981. Osmotic fragility and fluidity of erythrocyte membranes from rats raised on an essential fatty acid deficient diet. Biochim. Biophys. Acta 644, 175-182.

Faulkner, W.R., King, J.W., 1970. Manual of clinical laboratory procedures. Chemical Rubber Company, Cleaveland, USA.

Fischer, M.A., Black, H.S., 1991. Modification of membrane composition, eicosanoid metabolism, and immunoresponsiveness by dietary omega- 3 and omega- 6 fatty acid sources, modulators of ultraviolet-carcinogenesis. J. Photochem. Photobiol. 54, 381-387.
Hagve, T.A., Johansen, Y., Christophersen, B., 1991. The effect of n-3 fatty acids on osmotic fragility of rat erythrocytes. Biochim. Biophys. Acta 1084, 251-254.

Hagve, T.A., Lie, O., Gronn, M., 1993. The effect of dietary N-3 fatty acids on osmotic fragility and membrane fluidity of human erythrocytes. Scand. J. Clin. Lab. Invest. Suppl. 215, 75-84.

Hanzawa, K., Kai, M., Hiraga, A., Watanabe, S., 1999a. Fragility of red blood cells during exercise is affected by blood $\mathrm{pH}$ and temperature. Equine Vet. J. Suppl. 30, 610-611.

Hanzawa, K., Kubo, K., Kai, M., Hiraga, A., Watanabe, S., 1999b. Effects of exercise on density and osmotic fragility of circulating red cells in normal and splenectomised Thoroughbred horses. J. Equine Sci 10, 67-72.

Hanzawa, K., Watanabe, S., 2000. Changes in osmotic fragility of erythrocytes during exercise in athletic horses. J. Equine Vet. Sci. 11, 51-61.

Equine sports medicine and surgery. In: Hinchcliff, K.W., Kaneps, A.J., Geor, R.J. (Eds.), Saunders, London.

The athletic horse. In: Hodgson, D.R., Rose, R.J. (Eds.), Saunders Company, Philadelphia.

Ivanov, I.T., 1999. Investigation of surface and shape changes accompanying the membrane alteration responsible for the heat induced lysis of human erythrocytes. Colloids Surf. B 13, 311-323.

Kogawa, H., Yabushita, N., Nakajima, T., Kageyama, K., 1998. Studies on in vitro effect of free fatty acids on water content and osmotic fragility of rabbit (lepus cuniculus) erythrocytes. Life Sci. 62, 823-828.

O'Connor, C.I., Lawrence, L.M., Lawrence St, A.C., Janicki, K.M., Warren, L.K., Hayes, S., 2004. The effect of dietary fish oil supplementation on exercising horses. J. Anim. Sci. 82, 2978-2984.

Piccione, G., Arfuso, F., Fazio, F., Bazzano, M., Giannetto, C., 2014. Serum lipid modification related to exercise and polyunsaturated fatty acid supplementation in jumpers and thoroughbred horses. J. Equine Vet. Sci. 34, 1181-1187.

Pribush, A., Hatskelzon, L., Kapelushnik, J., Meyerstein, N., 2003. Osmotic swelling and hole formation in membranes of thalassemic and spherocytic erythrocytes. Blood Cell. Mol. Dis. 31, 43-47.

Shand, J.H., Noble, R.C., 1981. The maternal diet and its effect on the lipid composition and osmotic fragility of neonatal ovine erythrocytes. Biol. Neonate 40, 150-159. 
Smith, J.E., Erickson, H., Debowes, R.M., 1989. Changes in circulating erythrocytes induced by a brief, high-speed exercise. Equine Vet. J. 21, 444-446.

Smith, J.A., Kolbuch-Braddon, M., Gillam, I., Telford, R.D., Weidemann, M.J., 1995. Changes in the susceptibility of red blood cells to oxidative and osmotic stress following submaximal exercise. Eur. J. Appl. Physiol. Occup. Physiol. 70, 427-436.

Sowemimo-Coker, S.O., 2002. Red blood cell hemolysis during processing. Transfus, Med. Rev. 16, 46-60.

Stark, K.D., 2008. The percentage of n-3 highly unsaturated fatty acids in total HUFA as a biomarker for omega-3 fatty acid status in tissues. Lipids 43, 45-53. van den Berg, J.J.M., de Fouw, N.J., Kuypers, F.A., Roelofsen, B., Houtsmuller, U.M.T., den Kamp, J.A.F.O., 1991. Increased n-3 polyunsaturated fatty acid content of red blood cells from fish oil-fed rabbits increases in vitro lipid peroxidation, but decreases hemolysis. Free Radic. Biol. Med. 11, 393-399.

Walski, T., ChludziNska, L., Komorowska, M., Witkiewicz, W., 2014. Individual osmotic fragility distribution. A new parameter for determination of the osmotic properties of human red blood cells. Biomed. Res. Int. 2014, 6. http://dx.doi.org/ $10.1155 / 2014 / 162102$ 